\title{
Erken Çocukluk Döneminde Otizm Teşhisine Yönelik Dinamik Uzman Sistem Tasarımı
}

\author{
Hanife GÖKER ${ }^{1}$, İsmail ŞAHIN ${ }^{2}$, Hakan TEKEDERE ${ }^{3}$ \\ ${ }^{1}$ Bilişim Enstitüsü, Gazi Üniversitesi, Ankara, Türkiye \\ ${ }^{2}$ Teknoloji Fakültesi, Gazi Üniversitesi, Ankara, Türkiye \\ ${ }^{3}$ Sağlık Hizmetleri MYO, Gazi Üniversitesi, Ankara, Türkiye \\ hanifegoker@gmail.com, isahin@gazi.edu.tr, tekedere@gazi.edu.tr \\ (Geliş/Received: 12.05.2015; Kabul/Accepted: 27.07.2015) \\ DOI: $10.17671 / \mathrm{btd} .65517$
}

\begin{abstract}
$\ddot{O}_{z} \boldsymbol{e t}$ - Bu çalışmada; ilk defa erken çocukluk döneminde otizmin erken fark edilmesine yönelik bir dinamik uzman sistem geliştirilmiştir. Bu çalışmanın en önemli ayırt edici özelliği, uzman sistemlerin çıkarım mekanizması kısmında Naive Bayes algoritması kullanılarak kural tabanının dinamik olarak yenilenmesinin sağlanmasıdır. Bu sayede sistem daha önceden kayıtlı olmayan yeni bir durum ile karşılaştığında; mevcut kurallardan faydalanarak yeni kuralın hangi sınıfa ait olduğunu tahmin etmektedir. Geliştirilen dinamik uzman sistem; otistik bozuklukların belirtileri konusunda ailelerin bilgilendirilmesi, otistik çocuklara yönelik erken eğitim programlarının oluşturulması ve ailede yarattığı yıkıcı etkilere yönelik destek programlarının daha erken uygulanması gibi süreçlerde önemli katkılar sağlayacaktır.
\end{abstract}

Otizmin en etkili tedavi yöntemi olarak özel eğitim görülmektedir. Otistik bireylerin eğitiminde ve gelişiminde, eğitimin erken başlamasının olumlu sonuçları artırdığı bilinmektedir. Bireyin doğumundan itibaren otistik bozuklukların belirtileri görülebilmesine rağmen; ailelerin otizmi tanımaması, belirtilerini bilmemesi nedeniyle otizm tanısı genellikle 3 yaşından sonra, 4- 6 yaş arasında konmaktadır.

Otizmin erken tanısına yönelik olarak kullanılan belirtilerden hangilerinin var olduğuna karar vermek oldukça karmaşık ve deneyim gerektiren bir süreçtir. Bu nedenle, otizm erken tanısına yönelik yapay zekâ, uzman sistemler, karar destek sistemleri, veri madenciliği gibi teknikler kullanılabilir. Otizmin öncü belirtilerinin tanınması ve bu konudaki bozuklukların erken fark edilmesi, otistik çocuklara yönelik erken eğitim programlarının oluşturulması ve uygulanabilmesi açısından oldukça önemlidir.

Anahtar Kelimeler - Otizm, dinamik uzman sistem, naive bayes algoritması, erken tanı, çıkarım mekanizması

\section{Dynamic Expert System Design in Early Childhood Autism Diagnosis}

\begin{abstract}
For the first time with this study, a dynamic expert system has been developed for the early notice of autism in early childhood. The most important distinguishing feature of this study, by using Naive Bayes algorithm in the part of the inference engine of the expert system provides dynamically the renewal of the knowledge base. So that, when the system meets a new state which is not registered before; it estimates the new rule that belongs which class by using the current rules. Improved dynamic expert system will provide an important contribution in the process such as earlier implementation of support programs for the devastating impact that family, to inform families about the symptoms of autistic disorder and the creation of early education programs for children with autism,

Special education is seen as the most effective treatment for Autism. In development and training of autistic individuals, the early start of training is known to increase positive outcomes. Although symptoms of autistic disorder can be seen since birth; because of not knowing and not recognizing by families, the diagnosis of autism usually are set after the age of 3 , between 4 and 6 years of age.

To decide the symptoms used for the early diagnosis of autism is a very complex process that requires experience. Therefore, for the early diagnosis of autism can use techniques such as artificial intelligence, expert systems, decision support systems and data mining. Recognition of the early symptoms of autism and early recognition of the disorder is important for the creation and implementation of early education programs for children with autism spectrum disorders.
\end{abstract}

Keywords - Autism, dynamic expert system, naïve bayes algorithm, early diagnosis, inference mechanism 


\section{GİRIŞ (INTRODUCTION)}

Günümüzde bilgi ve iletişim teknolojileri sağlık sektöründe yaygın olarak kullanılmaktadır. Sağlık alanında bilgisayar temelli sistemler kullanılarak; klinik karar destek; teşhis ve tedavi sistemleri gibi birçok sistem oluşturulmuştur. Sayıları gerek ülkemizde, gerekse dünyada azımsanmayacak boyutta olan otistik bireylere yönelik bilgi sistemlerinin kullanımı sınırlı düzeydedir.

Otizm yaşamın erken dönemlerinde başlayan ve yaşam boyu süren karş1lıklı sosyal etkileşim ve iletişim becerilerinde yetersizlik, bilişsel gelişmede gecikme, basmakalıp davranışlar ve kısıtlı ilgi alanı ile karakterize nöropsikiyatrik bir bozukluktur [1, 2]. Otizm sadece otistik bireyi değil, ailesini, eğitimcilerini, içinde yasadığı sosyal çevreyi de etkileyen bir bozukluktur [3].

Otizmin kesin tanısı için kullanılan nesnel bir yöntem ya da biyolojik bir bulgu yoktur [4]. Tanı, gözleme dayanarak ve aileden alınan bilgilere göre konur. Otistik çocuğun davranışlarını sistematik olarak gözlemek ve aileye ayrıntılı sorular sorabilmek için bazı yöntemler ve ölçekler geliştirilmiştir [5] . Otizmin erken tanısı için nörolojik gelişim, sosyal etkileşim ve iletişim becerilerini içeren dikkatli bir öykü ve ayrıntılı bir fizik muayene önemlidir. Ailelere çocuklarının gelişimi ile ilgili endişeleri sorulmalı ve kaygıları varsa dikkatli değerlendirilmelidir [6].

Otizmde ortalama tanı yaşının 4-6 yaş arasında değiştiği bildirilmiştir. Oysa otizm tanısı almış çocuklar değerlendirildiğinde otizmle ilişkili bulguların 8-12. aylarda bile var olduğu saptanmıştır. Otizmin erken tanısı ile birlikte erken müdahalenin önemli ekonomik, akademik ve sosyal kazanımlara neden olduğu gösterilmiştir. Erken müdahale yapılan çocuklarda liseyi bitirme, iş sahibi olma, bağımsız yaşayabilme daha yüksek, adolesan gebeliğinden korunma ve suç işleme daha düşük bulunmuştur. Eğitim programları tanı konur konmaz, optimal 3 yaşından önce başlamalıdır çünkü 6 7' li yaşlardan sonra eğitimin olumlu katkıları çok az olmaktadır [7]. Şu anda uzmanlar tarafindan otizm teşhisi genellikle 3 yaşından itibaren konulmaktadır.

Uzman sistemler, insan uzmanlığı gerektiren problemlerin çözümünde kullanılan yazılımlardır. Otizmin teşhisine yönelik çalışmalar ancak klinik düzeyde sınırlıdır, otizmin erken teşhisine yönelik bir yazılım bulunmamaktadır. Otizmin belirtilerinin aileler tarafindan bilinmemesi, bulguların geç fark edilmesi erken tanı ve erken müdahaleyi geciktirmektedir. Erken çocukluk döneminde, otizmin belirtilerinin bilinmesi ve bu belirtilerden yola çıkılarak erken teşhis edilmesi otistik bireylere ve ailelerine destek eğitim programlarının geliştirilmesinde oldukça önemlidir.

Uzman Sistem yazılımları, belli bir algoritmaya dayanmayan, kendi bilgi tabanı içerisinde, girilen veya önceden belli olan verilere göre arama yaparak bu veriye veya verilere uygun olan bilginin (kuralın) aktifleşmesini sağlayan ve bu aktifleşme sonucu yeni bir veri elde ederek aramaya devam eden bir sistem şeklinde çalışmaktadır [8]. Bilgi tabanı, gerçekleştirilen uygulama ile ilgili olarak uzman kişinin bilgi ve tecrübelerinden hareketle oluşturulan bir dizi kural ve şart içerir. Kurallar, bilginin kullanımını kontrol eden yapılar olup, şartlar kullanıcılara yöneltilecek soruları veya karşılaşılabilir durumları içeren ifadelerdir [9, 10].

Literatürde sağlık alanında birçok farklı problem alanları için uzman sistem tasarımı geliştirilmiştir. Bu uzman sistemler kullanılarak insan uzmanlığ 1 gerektiren problemlerin çözümünde karar verme işlemlerini modelleyebilmekte, etkili, hızlı ve doğru kararlar verilebilmektedir. Bu çalışmalara örnek olarak; boğaz enfeksiyonlarının teşhis ve tedavisinde uzman sistem kullanılması[11], internet tabanlı bulanık girişli uzman sistem tasarımıyla mikrobiyoloji tahlil sonuçlarının yorumlanması[12], demir eksikliği anemisi teşhisi için bir bulanık uzman sistem tasarlanması [13] ve uzman sistemlerin tiroit teşhisinde kullanılması[14] gösterilebilir.

$\mathrm{Bu}$ çalışma ile ilk defa otizmin erken teşhisine yönelik dinamik uzman sistemin kullanılması ve otizmin 3 yaş altında erken teşhisine imkân tanınması yönleriyle bu alanda yürütülen çalışmalara yenilik katmaktadır. Çalışmada, otistik bozuklukların belirtileri konusunda ailelerin bilgilendirilmesi, 3 yaşından önce otizmin erken tanısının sağlanması, sabit kural tabanı yerine dinamik kural tabanı ile sistemde kayıtlı kural olmasa bile dinamik kural tablosunu yenileyen bir dinamik uzman sistemin geliştirilmesi amaçlanmıştır.

\section{NAIVE BAYES ALGORITMASI(NAIVE BAYES ALGORITHM)}

Naive Bayes, Bayes karar teorisine dayalı olasılıksal bir sınıflandırma algoritması olup geçmiş bilgilerin hangi sınıflara ait olduğu verildiğinde yeni gelen verinin hangi sınıfa dâhil olduğunun bulunmasında kullanılır [15]. Naive Bayes, modelin öğrenilmesi esnasında, her çıktının öğrenme kümesinde kaç kere meydana geldiğini hesaplar [16]. Naive Bayes algoritmasının, üst seviyede iyi sonuç vermesi, gerçekleşmesinin kolay olması yüksek doğruluk, kesin ve hızlı sonuçlar üretmesi, algoritmanın basit ve anlaşılabilir olması avantajları arasında sayılabilir.

Naive Bayes algoritmasında; sınıfı belirlenecek olan örneğe ilişkin olarak aşağıdaki bağıntılar kurulur. Sınıfı belirlenecek olan örneğe ilişkin olarak olasılıkları hesaplanır [17];

$$
P\left(C_{j} \mid X\right)=\frac{P\left(X_{C_{j}}\right)}{P\left(C_{j}\right)}
$$


Hesaplamalardaki işlem yükünü azaltmak üzere $\mathrm{P}(\mathrm{X} \mid \mathrm{Ci})$ olasılığ 1 için basitleştirme yoluna gidilebilir. Bunun için, örneğe ait Xi değerlerinin birbirinden bağımsız olduğu kabul edilerek șu bağıntı kurulabilir:

$$
P\left(X \mid C_{j}\right)=\prod_{\mathrm{k}=1}^{\mathrm{n}} \mathrm{P}\left(\mathrm{X}_{\mathrm{k}} \mid \mathrm{C}_{\mathrm{j}}\right)
$$

Bilinmeyen örnek $X^{\prime}$ i sınıflandırmak için 2. 1' de $\mathrm{P}(\mathrm{Ci} \mid \mathrm{X})$ içinde yer alan paydalar birbirine eşit olduğu için sadece pay değerlerinin karşılaştırılması yeterlidir. $\mathrm{Bu}$ değerler içerisinden en büyük olanı seçilerek bilinmeyen örneğin bu sınıfa ait olduğu belirlenmiş olur.

$$
\underset{\mathrm{C}_{i}}{\arg \max }\left\{P\left(X \mid C_{j}\right) P\left(C_{j}\right)\right\}
$$

Sonrasal olasılıkları kullanan yukarıdaki ifade, en büyük sonrasal sınıflandırma yöntemi ( Maximum A Posteriori Classification $=$ MAP) olarak ta bilinir. $\mathrm{O}$ halde sonuç olarak 2. 1 ve 2.2 den dolayı, Naive Bayes sınıflandırıcısı olarak aşağıdaki bağıntı kullanılabilir:

$$
\mathrm{C}_{\mathrm{MAP}}=\underset{\mathrm{C}}{\operatorname{argmax}} \prod_{\mathrm{k}=1}^{\mathrm{n}} \mathrm{P}\left(\mathrm{X}_{\mathrm{k}} \mid \mathrm{C}_{\mathrm{i}}\right)
$$

Naive Bayes sınıflandırma algoritmasında, her bir olasılık değerinin sıfırdan büyük olması gerekir, aksi takdirde bütün olasılık sıfır olur.

Olasılığın sıfır olması durumunu, önlemek için k gibi küçük bir değer her orana eklenir. Her bir $\frac{n}{d}$ oranına $\mathrm{k}$

$$
n+k p
$$

sayısının ilave edilmesiyle $\overline{d+k}$ bağıntısı elde edilir. Burada $\mathrm{k}$ ilave edilecek sayı, $\mathrm{p}$ ise 0 sorununa neden olan kriterin farklı değer sayısıdır [17]. Eklenen sayı, veri seti büyük olduğu için sonucu çok fazla etkilemez.

\section{OTIZM TANISINA YÖNELIK GELIŞTİIILEN DİNAMIKK UZMAN SISTEM BİLESENLERİ(THE IMPROVED DYNAMIC EXPERT SYSTEM COMPONENTS)}

Otizm tanısına yönelik geliştirilen dinamik uzman sistem; otistik bozukluk bilgi tabanı, çıkarım mekanizması ve açıklama birimi olmak üzere üç ana kısımdan meydana gelmektedir.

\subsection{Geliştirilen Dinamik Uzman Sistemin Yapısı(The}

Improved Dynamic Expert System)

Çalışmada kural tabanı; uzman görüșleri, literatür taraması ve otistik bozuklukları belirlemek için kullanılan Otizm belirleme ölçekleri doğrultusunda edilen bilgilerin analiz edilmesiyle oluşturulmuştur.

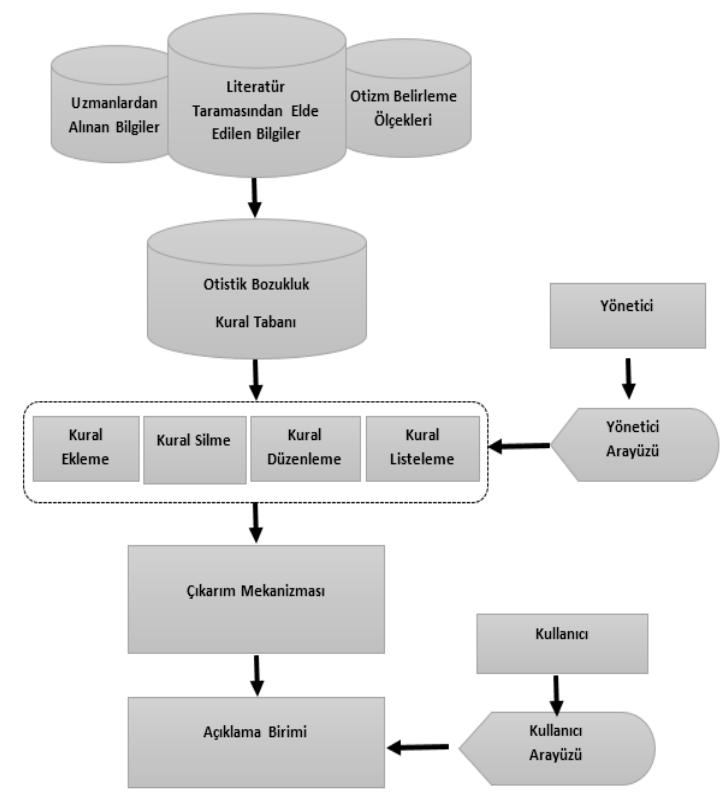

Şekil 1. Geliştirilen Dinamik Uzman Sistem Tasarımı Akış Şeması (Improved Dynamic Expert System Design Flowchart)

Yazılım bilgi tabanı oluşturma, verilerin görüntülenmesi, çıkarım mekanizması ve açıklama birimi olmak üzere dört alt bileşenden oluşmaktadır.

Geliştirilen uzman sistemde, kuralların girildiği, kuralların grafiksel olarak gösterildiği, kuralların listelendiği, otistik bozukluk tanısının yapıldığı, açıklama biriminin bulunduğu formlar ile bu formların hepsine ulaşım sağlayan bir ana form bulunmaktadır. Yazılım ilk çalıştırıldığında kullanıcıların karşısına Şekil 2' de yer alan ana form gelmektedir.

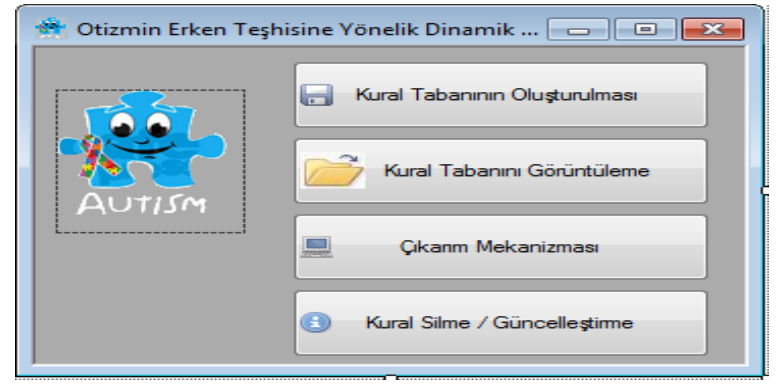

Şekil 2. Ana form (The main form)

\subsection{Bilgi Tabant(Knowledge Base)}

Yazılımdaki bilgi tabanı oluşturulurken; otizm belirleme ölçeklerinden alınan veriler, otizm konusundaki uzman 
görüşleri, literatür taramasından elde edilen veriler kullanılmıştır.

Yazılımda, ilk olarak "Kural Tabanı Olușturulması" seçeneği tıklanarak otistik bozukluk belirtilerinin girildiği kural tabanı oluşturulmaktadır. $\mathrm{Bu}$ kısım kullanıcının, bilgi girişlerini daha rahat bir şekilde yapmasını ve kolaylıkla bilgi tabanını oluşturmasını sağlamaktadır. Otistik bozukluklara ait kuralların girildiği form; "Genel Bilgiler", "Oyun Oynama”, "Davranışsal-Tepkisel”, "Gösterme-İşitme" olmak üzere birbirini takip eden dört kısımdan oluşmaktadır. Söz konusu form Şekil 3.' de gösterilmiştir.

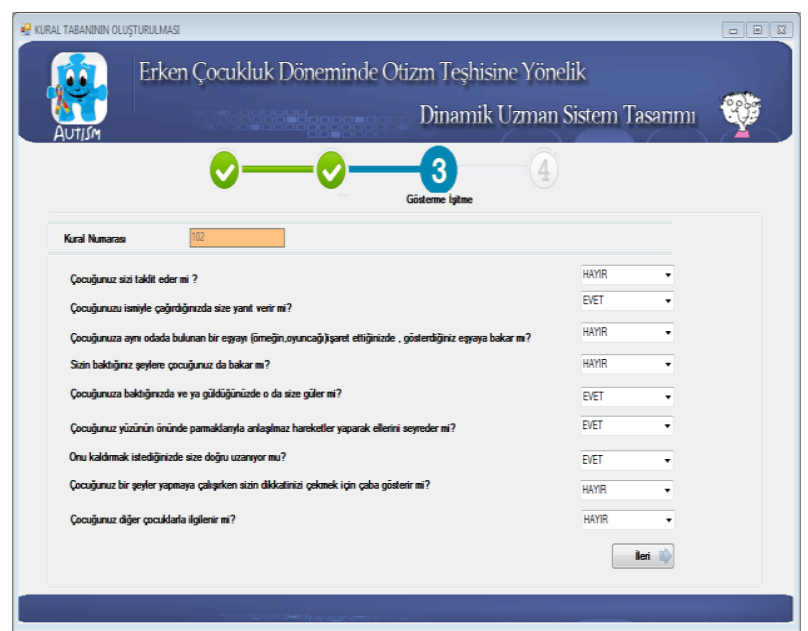

Şekil 3. Bilgi Tabanı oluşturma formu (Knowledge base form)

Bilgi Tabanı oluşturma formunda, 100 adet kural girilerek bilgi tabanı oluşturulmuştur. Bilgi tabanında 29 adet nitelik ve 1 sınıf (class) bilgisi bulunmaktadır.

Bilgi Tabanı olușturulduktan sonra, Şekil 4.' de verilerin görüntülenmesi kısmında; kural tabanında bulunan kurallar silinebilir, yeni kurallar eklenebilir, mevcut kurallar güncellenebilir, kurallar listelenebilir ve her bir niteliğe ait kurallar grafiksel olarak gösterilebilmektedir.

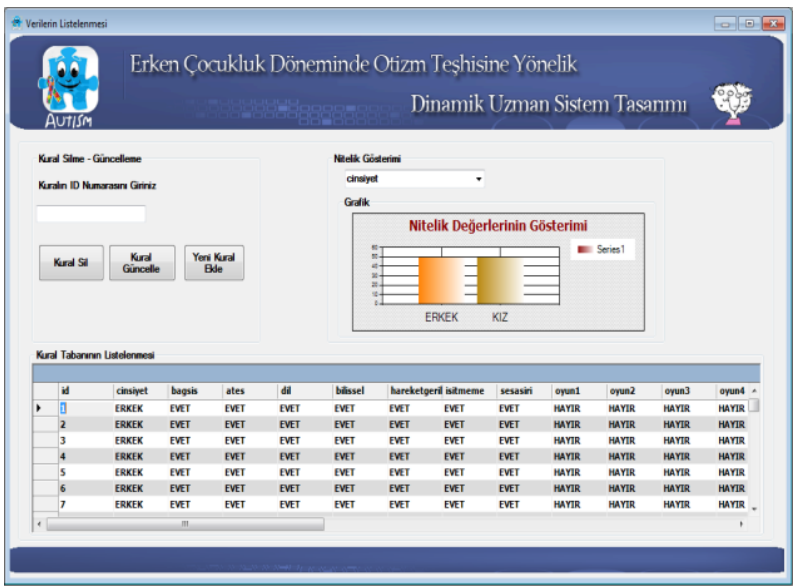

Şekil 4. Kuralları görüntüleme/silme/güncelleme formu (Rules view / delete / update form)

\section{3. Çıkarım Mekanizması (Inference Mechanism)}

Çıkarım mekanizmasının görevi bilgi tabanını yorumlama ve kontroldür. Çıkarım mekanizması, kurallar tabanındaki kuralların kullanılarak anlamlı çıkarımların yapıldığı birimdir [18]. Geliştirilen uzman sistemde çıkarım mekanizması olarak Naive Bayes siniflandirma algoritması kullanmakta ve kural tabanı kendini yenileyebilen dinamik bir yap1 arz etmektedir. Yeni bir durumla karşılaşıldığında; mevcut kural kümesinde kural varsa o kural işletilir, eğer kural kümesinde o kural yok ise geliştirilen dinamik uzman sistem ile mevcut kural tabanından yararlanarak sonucun öngörülmesi sağlanmaktadır.

Geliştirilen uzman sistemin mevcut çalışmalardan en önemli farkı otomatik kural tabanının oluşturulmasıdır.

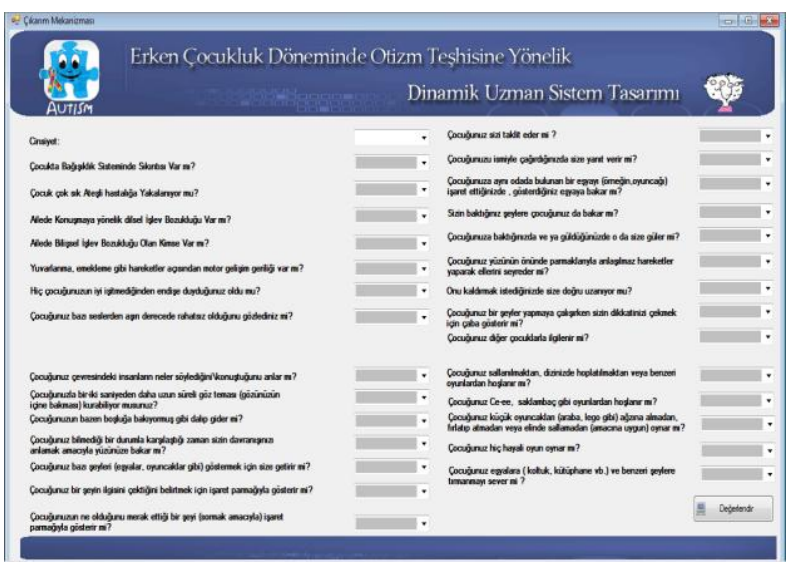

Şekil 5. Çıkarım mekanizması formu (Inference mechanism form)

Sistem yeni bir durumla karşılaştığında Naive Bayes algoritması kullanarak veritabanındaki mevcut kural tabanını öğrenir ve tüm olasılıkları hesaplayarak yeni kural tabanını oluşturur. Uygulamada, ilk olarak sistem Naive Bayes algoritması kullanılarak mevcut kural tabanı ile eğitilmektedir. Yeni bir durum ile karşılaşıldığında ilk olarak mevcut kural tabanı çekilerek her bir sınıfa ait ihtimal durumu (Autism, Normal) için Şekil 5' de gösterilen formda yer alan Combobox nesnelerinden seçilen nitelik değerlerinin frekans sayıları hesaplatılmaktadır. Her bir sınıfa ait sonucun çıkma olasılığ 1 , o sonucu etkileyen tüm niteliklerin, o sınıfa ait sonucu sağlama olasılıklarının çarpımıdır. Naive Bayes algoritmasında her bir olasılığın sıfırdan büyük olmasını gerekir, aksi takdirde bütün olasılık sıfir olur, bu nedenle yazılımda her bir olasılığın sıfirdan farklı olup olmaması kontrol edilmekte, olasılık 0'a eşitse sonucu değiştirmeyecek kadar küçük bir değer eklenmektedir.

Sonuç olarak her bir sınıf bilgisine ait ihtimaller karşılaştırılarak yeni kuralın eğer "Autism” sınıf bilgisine ait ihtimal daha yüksekse "Autism" sinıfina, eğer "Normal" sınıfına ait ihtimal daha yüksekse "Normal" sınıfına atamaktadır. Her olasılık için sonuçlar hesaplanmakta ve en yüksek olasılığa sahip olan sınıfa 
yeni kural atanmaktadır. Hesaplanan belirti olasılığına göre sonuç kullanıcıya açıklama biriminde mesaj kutusu ile gösterilmektedir.

Yapılan çalışmanın çıkarım mekanizmasının Pseudo kodu aşağıda verilmiştir:

1. Her bir sınıfa ait kural sayısının hesaplanması

2. Hesaplanacak her bir nitelik için her bir sınıfa ait olma olasılığının hesaplanması

3. Sonucun sifir olma olasılığının ortadan kaldırılması

4. Otizm belirtisinin olması (p) veya olmaması(q) oranlarinın hesaplanmasi

5. Eğer $\mathrm{p}$ oranı $>\mathrm{q}$ oranı ise kuralın "Autism” sınıfına değilse "Normal" sınıfına atanması

6. Sonuçların kullanıcıya açıklama biriminde gösterilmesi

\subsection{Açıklama Birimi (Description Unit)}

Açıklama birimi, elde edilen sonuçların kullanıcılara iletildiği bölümdür. Bir uzman sistem, bilgi tabanını kullanarak elde ettiği çıkarımı açıklayabilme özelliğine sahip olmalıdır [19]. Geliştirilen uzman sistemde açıklama birimi, otizm belirtilerinin görülüp görülmediği kullanıcıya Şekil 6' da görüldüğü gibi bir mesaj kutusu ile gösterilmektedir.

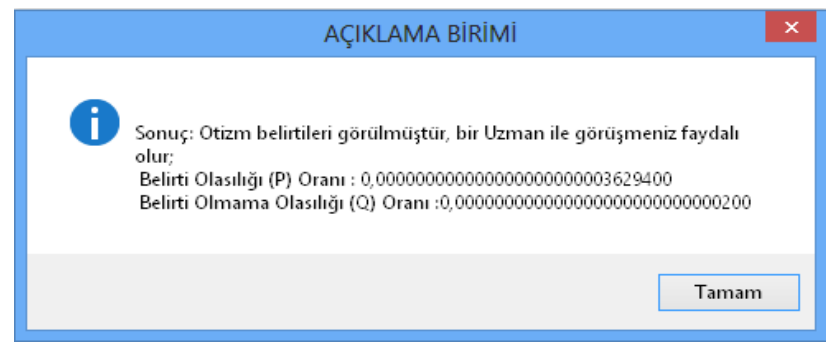

Şekil 6. Açıklama birimi mesaj kutusu (Description unit message box)

Çalışmada; otizmin erken çocukluk döneminde teşhis edilmesine yönelik, kuralların eklenebildiği, grafiksel olarak görüntülenebildiği, listelenebildiği, kural tabanında olmayan bir kural ile karşılaşıldığında, kural tabanını dinamik şekilde yenileyebildiği bir uzman sistem geliştirilmiştir.

Literatürde konu ile ilgili çalışmalarda, hastalık teşhisine yönelik uzman sistemlerin kullanıldığı görülmektedir [11, 13, 14]. Yapılan çalışmalarda tiroit teşhisi [14], epileptik hastalıkların teşhisi[20], tüberküloz tanısı [21], meme kanseri tanısı[22], akciğer kanseri tanısı [23] ve prostat kanser riskinin tespiti [24] gibi birçok hastalık teşhislerinde uzman sistemler kullanılarak etkili sonuçlar elde edilmiştir. Hastalıkların tanısında uzman sistem kullanan bu çalışmalarda; benzer şekilde hastalıkların tanısında uzman sistemlerin kullanılabileceği rapor edilmiştir.

\section{SONUÇLAR (CONCLUSIONS)}

$\mathrm{Bu}$ çalışmada otistik olma ihtimalinden şüphelenilen çocukların otistik olup olmadıklarını tespit etmede birinci seviye sağlık kuruluşlarındaki aile hekimlerinin konu uzmanlarına yönlendirme yapması açısından destek verici ve aynı zamanda konu uzmanlarına da tam tanı koymada kolaylık sağlayıcı bir uzman sistem tasarlanmıştır.

Geliştirilen dinamik uzman sistem yazılımının; otizmin belirtileri konusunda ailelerin bilgilendirilmesine, hem otistik bireyler hem de aileleri için erken eğitim programlarının oluşturulmasına, otizmin ailede yarattığı yıkıcı etkilere yönelik destek programlarının daha erken uygulanmasına imkân vereceği düşünülmektedir.

Çalışma kapsamında elde edilen sonuçlar aşağıda listelenmiştir:

- Uzmanlardan, literatür taramasından ve otizm belirleme ölçeklerinden alınan bilgiler ile "Otistik Bozukluk Kural Tabanı” oluşturulmuştur.

- Geliştirilen uzman sistem ile ailelerin çocuklarında otizm belirtilerinin olup olmadığ konusunda bilgilendirilmeleri sağlanmaktadır.

Sisteme yeni kurallar eklenebilmekte, mevcut kurallar silinip, düzenlenebilmekte ve grafiksel olarak görüntülenebilmektedir.

- Sistem, otizmin erken çocukluk döneminde teşhisine yönelik hem uzmanlar hem de aileler açısından kolaylıklar sağlamaktadır.

- $\quad$ Sistemin çıkarım mekanizmasında Naive Bayes algoritması kullanılmıştır. $\mathrm{Bu}$ sayede sistem mevcut kural tabanı ile eğitilerek yeni kurallar üretebilmektedir. Başka bir ifadeyle kural tabanı yeni bir durum ile karşılaşılması halinde dinamik olarak yeni kural oluşturabilmektedir.

Geliştirilen dinamik uzman sistem; otizm ile ilgili alan uzmanlarına yardımcı olmak, otistik bireylerin şikâyet ve tanı bilgileriyle ilgili bir veritabanı oluşturmak, ailelerin otistik bozuklukların belirtileri hakkında farkındalığını arttırmak ve otizmin erken tanısina destek olmak amaciyla kullanılabilir. Geliştirilen uzman sistem yazılımının bilgi tabanındaki kuralları değiştirilerek farklı problemlerin çözümünde de kullanılması sağlanabilir.

Tasarlanan sistemin web üzerinden ulaşılabilir hale getirilmesiyle konu uzmanlarının kullanımına açılmasının, sistemde hali hazırda var olan kuralların en ideal biçimini almasına katkı sağlayacağ düşünülmektedir. En ideale yaklaşan kurallar sayesinde tüm ihtimallerin sürece katılmasıyla söz konusu uzman 
sistemin daha hızlı ve daha kesin otizm tanısının koyulmasına önemli oranda yardımcı olacağ düşünülmektedir.

\section{TEŞEKKÜR (ACKNOWLEDGMENT)}

Çalışmada Otizm sendromunun erken teşhisine yönelik kuralların oluşturulmasında katkıda bulunan Rehberlik ve Psikolojik danışman Deniz SADAY' a teşekkür ederiz.

\section{KAYNAKLAR (REFERENCES)}

[1] American Psychiatric Association, Diagnostic and Statistical Manual of Mental Disorders (DSM IV), Washington, DC: American Psychiatric Association Press, 1994.

[2] A. Kulaksızoğlu, Farklı Gelişen Çocuklar, Epsilon Yayıncılık, İstanbul, 2003.

[3] S. Alpaytaç, Otizm üzerine Türkiye'den bir örnek vaka incelemesi, Yüksek Lisans Tezi, Yedi Tepe Üniversitesi, Sosyal Bilimler Enstitüsü, 2007.

[4] C. D. Prater, R.G. Zylstra, "Autism: A medical primer", American Family Physician, 66(9), 1667-1674, 2002.

[5] B. Korkmaz, Asperger Sendromu, Adam Yayınları, İstanbul, 2003.

[6] E.G. Stubbs, K. Cheng, "Autism Spectrum Disorders", Child and Adolescent Psychiatry, K. Cheng, K.M. Myers (Ed.). Philadelphia: Lippincott Williams \&Wilkins, (s.227-246), 2005.

[7] B. Kara, İstanbul'da yaygın gelişimsel bozuklukların tanısında m-chat testinin geçerliliği, Uzmanlık Tezi, İstanbul Üniversitesi, Tıp Fakültesi, 2009.

[8] N. Allahverdi, Uzman Sistemler: Bir Yapay Zeka Uygulaması Atlas Yayıncılık, İstanbul, 16-20, 2002.

[9] A. S. Anagün, "Selecting Inventory Models Using an Expert System", Computers and Industrial Engineering, 33 (1-2), 299-302, 1997.

[10] M. Albayrak, Ș. Taşdemir, N. Allahverdi, "An Expert System Approach to Determine The Computer Hardware Failures", The International Conference on Modeling and Simulation AMSE2006, 28-30 Aug 2006, pp. 559-563, Selçuk Üniversitesi-Konya, Turkey.

[11] A. Babalık, İ. Güler, "Boğaz enfeksiyonlarının teşhis ve tedavisinde uzman sistem kullanımı", Selçuk Üniversitesi Teknik Bilimler Meslek Yüksekokulu Teknik-Online Dergi Cilt 6, Sayı:2-2007.

[12] F. Başçiftçi, H. İncekara, "İnternet tabanlı bulanık girişli uzman sistem tasarımıyla mikrobiyoloji tahlil sonuçlarının yorumlanması" Selçuk Üniversitesi Teknik - Online Dergisi, Cilt10 sayı: 1, 2011.

[13] A. Yılmaz, Demir eksikliği anemisi teșhisi için bir bulanık uzman sistem tasarlanması, Yüksek Lisans Tezi, Selçuk Üniversitesi, Fen bilimleri Enstitüsü, 2012.

[14] A. Keleş, A. Keleş, “ESTDD: Expert system for thyroid diseases diagnosis”, Expert Systems with Applications, 34(1), 242-246, 2008.
[15] M. F. Amasyalı, Yeni makine öğrenmesi metotları ve ilaç tasarımına uygulamaları, Doktora Tezi, Yıldız Teknik Üniversitesi, Fen Bilimleri Enstitüsü, İstanbul, 2008.

[16] S. Akbulut, Veri madenciliği teknikleri ile bir kozmetik markanın ayrılan müşteri analizi ve müșteri segmentasyonu, Yüksek Lisans Tezi, Gazi Üniversitesi, Fen Bilimleri Enstitüsü, 2006.

[17] Y. Özkan, Veri Madenciliği Yöntemleri, Papatya Yayıncılık, İstanbul, 2008.

[18] M. Erkalan, M. H. Calp, İ. Şahin, "Çoklu zekâ kuramından yararlanılarak meslek seçiminde kullanılacak bir uzman sistem tasarımı ve gerçekleştirilmesi”, International Journal Of Informatics Technologies, 5(2), 49-55, 2012.

[19] İ. Şahin, M. H. Calp, A. Özkan, "An expert system design and application for hydroponics greenhouse systems", Gazi University Journal of Science, 27(2), 809-822, 2014.

[20] Y. Kaya, R. Tekin, "Epileptik hastalıkların teşhisi için aşırı öğrenme makinesi tabanlı bir uzman sistem”, International Journal Of Informatics Technologies, 5(2), 33-40, 2012.

[21] V. C. Osamor, A. A. Azeta, O. O. Ajulo, "TuberculosisDiagnostic Expert System: An architecture for translating patients information from the web for use in tuberculosis diagnosis", Health informatics journal, Vol. 20(4) 275-287, 2014.

[22] A. Keleş, A. Keleş, U. Yavuz, "Expert system based on neurofuzzy rules for diagnosis breast cancer", Expert Systems with Applications, 38(5), 5719-5726, 2011.

[23] E. Avc1, "A new expert system for diagnosis of lung cancer: GDA-LS_SVM”, Journal of medical systems, 36(3), 2005-2009, 2012 .

[24] M. Çınar, Prostat kanser riskinin tespitinde sınıflandırıcı tabanlı uzman sistem kullanımı, Yüksek Lisans Tezi, Ege Üniversitesi, Fen Bilimleri Enstitüsü, 2007. 